\begin{tabular}{|c|c|}
\hline Title & Effects of mutation of A sn694 in A spergillus niger a -glucosidase on hydroly sis and transglucosylation \\
\hline Author(s) & $\begin{array}{l}\text { Ma, Min; Okuy ama, Masay uki; Sato, Megumi; T agami, T akay oshi; Klahan, Patcharapa; Kumagai, Y uya; Mori, } \\
\text { Haruhide; Kimura, A tsuo }\end{array}$ \\
\hline Citation & $\begin{array}{l}\text { A pplied microbiology and biotechnology, 101(16), 6399-6408 } \\
\text { https://doi.org/10.1007/s00253-017-8402-6 }\end{array}$ \\
\hline Issue Date & 2017-08 \\
\hline Doc URL & http:/hdl.handle.net/2115/71157 \\
\hline Rights & The final publication is available at link.springer.com via http://dx.doi.org/10.1007/s00253-017-8402-6 \\
\hline Tyре & article (author version) \\
\hline Additional Information & There are other files related to this item in HUSCAP. Check the above URL. \\
\hline File Information & Supplementary.pdf \\
\hline
\end{tabular}

Instructions for use 
Applied Microbiology and Biotechnology

Supporting Information for

\section{Effects of mutation of Asn694 in Aspergillus niger a-glucosidase on hydrolysis and transglucosylation}

Min Ma, Masayuki Okuyama*, Megumi Sato, Takayoshi Tagami, Patcharapa Klahan, Yuya Kumagai, Haruhide Mori, and Atsuo Kimura*

Research Faculty of Agriculture, Hokkaido University, Sapporo 060-8589, Japan

* Authors for correspondence:

Masayuki Okuyama;

e-mail, okuyama@abs.agr.hokudai.ac.jp; tel, +81-11-706-2816; fax, +81-11-706-2808

Atsuo Kimura;

e-mail, kimura@abs.agr.hokudai.ac.jp; tel and fax, +81-11-706-2808 


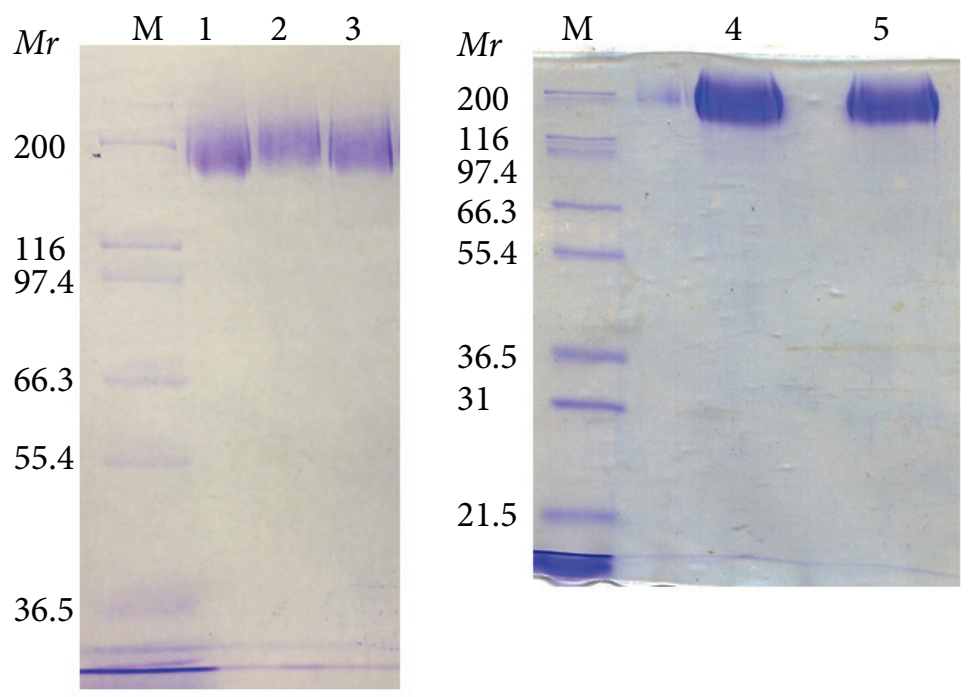

Figure S1. SDS-PAGE gel with Coomassie Brilliant Blue staining of the purified wild-type and mutant ANGs. Positions of Marker proteins (M) and molecular weight are shown on the side. Lane 1, wild type; lane 2, N694L; 3, N694W; 4, N694A; 5, N694F. 
A

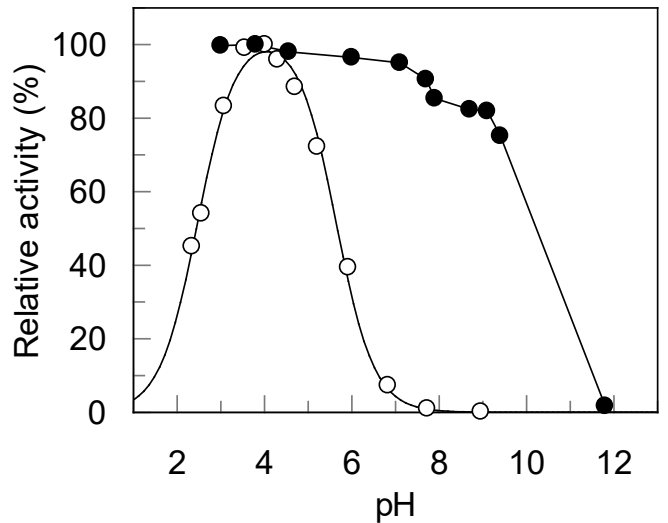

C

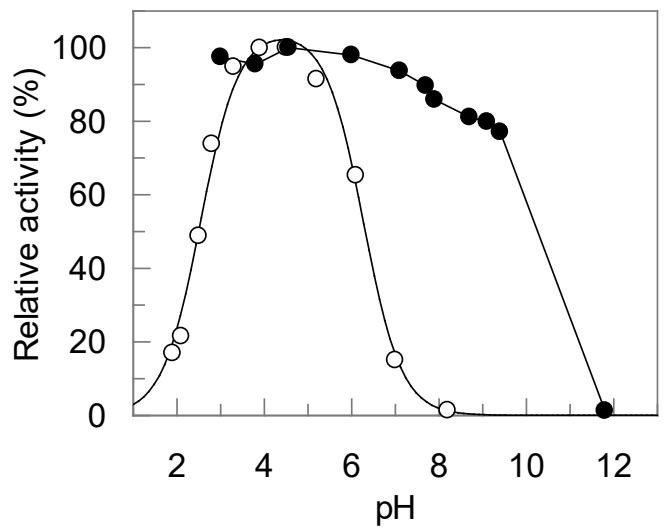

E

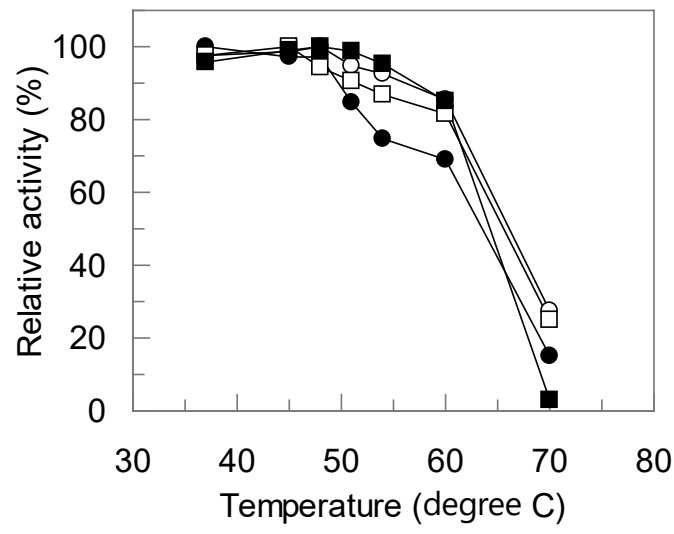

B

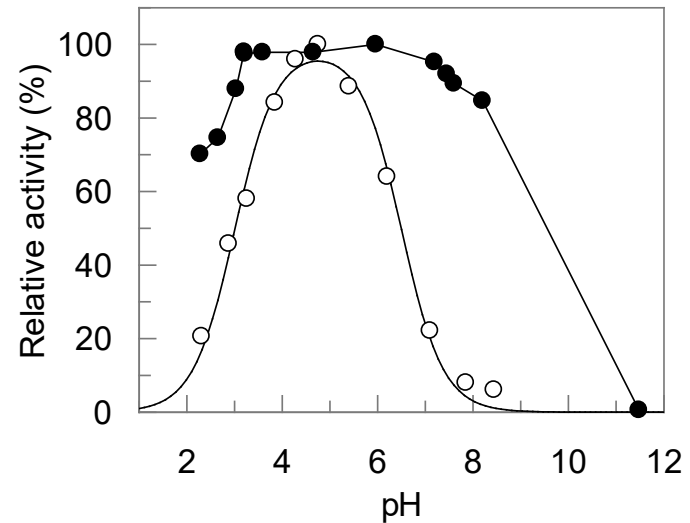

$\mathrm{D}$

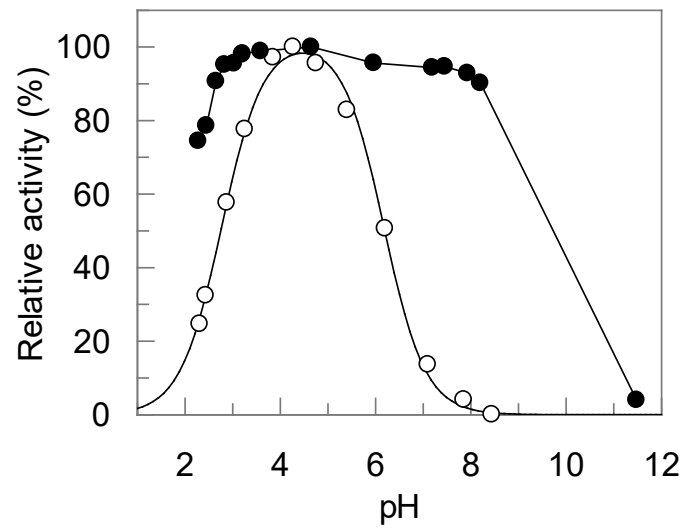

Figure S2. pH-activity ( $($ ) and -stability (•) of N694A (A), N694L (B), N694F (C), and N694W (D); and thermal stability of mutant enzymes (E). 
A

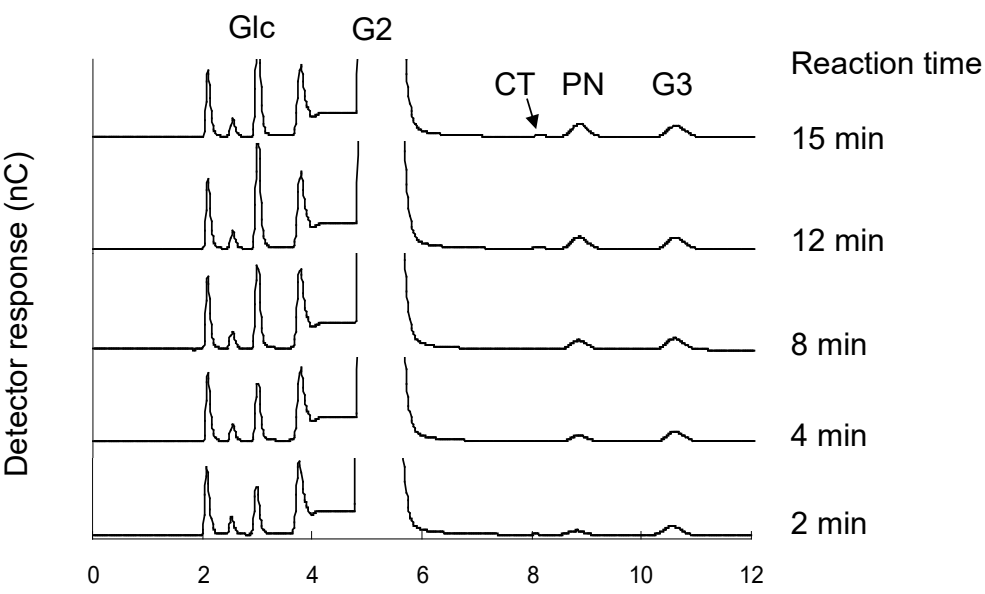

B

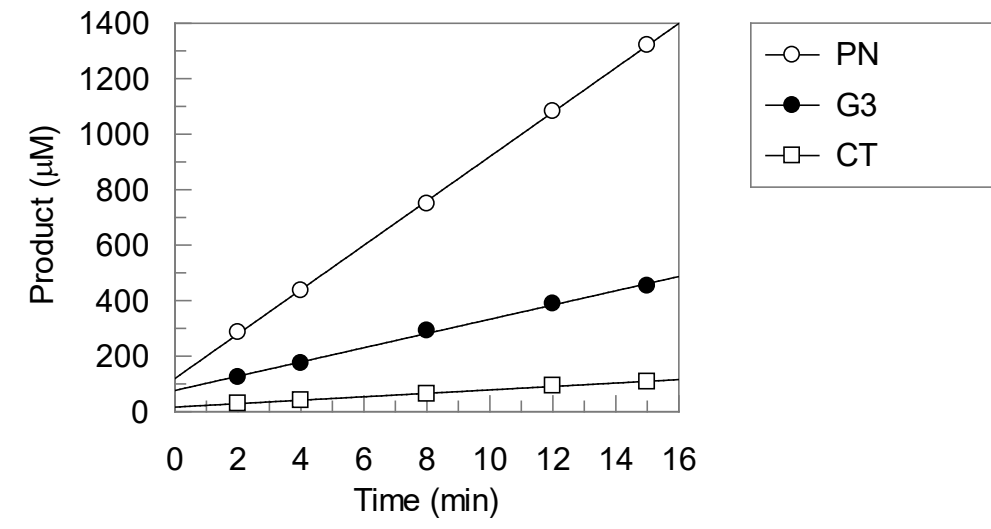

Figure S3. HPAEC-PAD analysis of the reaction products by wild-type ANG with $100 \mathrm{mM} \mathrm{G2}$ (A) and progress curve of the transglucosylation products, PN (०), G3 (•), and CT ( $\square)$. 